\title{
The Acquisition of English and Arabic Onset Cluster: A Case Study
}

\author{
Hana A. Daana ${ }^{1} \&$ Sura M. Khrais ${ }^{1}$ \\ ${ }^{1}$ Department of English Language and Literature, Princess Alia University College/ Al-Balqa Applied University, \\ Amman-Jordan \\ Correspondence: Hana A. Daana, Department of English Language and Literature, Princess Alia University College/ \\ Al-Balqa Applied University, P.O.Box: 184556, Postal Code: 11118, Amman-Jordan
}

Received: December 29, 2017

Accepted: January 28, 2018

Online Published: January 30, 2018

doi:10.5430/elr.v7n1p13

URL: https://doi.org/10.5430/elr.v7n1p13

\begin{abstract}
This study has investigated the development of English and Arabic onset cluster in the speech of a bilingual child. Data was related to several recording sessions of spontaneous and non-spontaneous speech between the first author and her own child. The gradual development of English and Arabic onset cluster was traced in the production of a bilingual child aged between 1 year 04 months and 4 years 06 months. A comparative description of the repair strategy types used by the child to break English and Arabic consonants clustering in word-initial position has been provided. English onset clusters started to appear before Arabic clusters. Arabic core clusters appeared before plateau and reversal clusters. Cluster reduction and epenthesis were used to simplify the clusters in both languages and prothesis was used in Arabic.
\end{abstract}

Keywords: Acquisition, Arabic, Bilingual, English, Repair Strategies, Onset Cluster

\section{Introduction}

Consonant clusters are considered some of the difficult speech targets in the process of first language acquisition due to the child's internal preference of the syllable structure composed of a consonant followed by a vowel (CV). It is significant to understand the order in which onset clusters emerge in the speech of bilingual children. It is also important to investigate the way bilingual children symplify onset clusters in their two first languages in order to make them 'appropriate' in terms of the universal CV structure they prefer. Hide's study revealed that targeting cluster can result in wide change in the phonologies of the children (2007). There is a difference in the preferences of cluster simplification strategies among the children acquiring different languages. In order to avoid onset clusters, children insert an epenthetic vowel between the consonants as in [k/ja:b] instead of $/ \mathrm{kla}: \mathrm{b} / \operatorname{dog} s$. Another modification strategy is the deletion of one segments of the cluster as in [ka:b] instead of /kla:b/ dogs. Such strategies are used by children to make the pronunciation of the words easy.

\subsection{Onsets and Syllable Structure}

The sequence of consonants in a syllable is restricted by the possible phonotactic constraints and phonological rules of a language. The sonority of the segments is one of the factors that constraint the tautosyllabic clusters (clusters within the same syllable). The nucleus is the sonority peak of a syllable within the internal structure of a syllable. It is expected that the value of sonority decreases the farther segment is from the nucleus and increases when it gets closer to the nucleus (Ladefoged, 2006). This is phonologically referred to as the Universal Sonority Sequencing Principle (SSP), which entails that onsets rise in sonority and codas fall in sonority (Clements, 1990).

Many proposals have suggested a number of competing sonority scales. Universal sonority scales, given to the natural classes, have been suggested by different studies conducted by Butt (1992), Clements (1990), and Selkirk (1984). Clements (1990) posited a complexity ranking based on the sonority scale $\mathrm{O}<\mathrm{N}<\mathrm{L}<\mathrm{G}<\mathrm{V}$ (where, $\mathrm{O}$ stands for Obstruent that includes Stops and Fricatives, $\mathrm{N}$ for Nasal, L for Liquid, G for Glide, and V for Vowel). This sonority scale implies the unmarked order of segment types within an initial demi syllable known as ONLGV.

Hammond (1999) also proposed an onset ranking that distinguishes the most preferred onset clusters from the least preferred ones. On the two poles of the continuum, the most preferred onset cluster is the one that is formed by an obstruent (stop or fricative) followed by an approximant. On the other hand, the least preferred onset cluster is the one that is formed by an approximant followed by an obstruent. According to Hammond (1999), universally preferred onset clusters are arranged from the most preferred to the least preferred as follows: 
Obstruent + Approximant

Obstruent + Nasal

Nasal + Approximant

Nasal + Obstruent

Approximant + Nasal

Approximant + Obstruent

The most marked sequence, i.e., the least preferred, is approximant + obstruent. In contrast, the sequence obstruent + approximant is the unmarked sequence that is the most preferred sequence.

\subsection{Comparison of Types of Onset Cluster in English and Arabic}

One major difference between English and Arabic syllable structure is that English allows syllables with no onsets; while, Arabic does not. English also allows onset cluster composed of two or three consonants. English structure of onsets may be represented as (C) (C) (C) V. Watson (2002) referred to the clusters that obey the SSP as 'core cluster'. English mostly allows the clusters that comply with the SSP. Carr claimed that "only [s]-initial onsets violate the sonority hierarchy" (1999:73). Hence, it occurs in sequences such as 'street' and 'sky'.

Arabic in general and Ammani Arabic in particular does not allow syllables without onsets. Basically, onsets are obligatory elements in the syllable structure of Ammani Arabic. Ratcliffe (1998) stated that one of the syllable structure constraints in Arabic is that each syllable should begin with one consonant. Consonant clusters in onset position are permissible in Ammani Arabic. Ammani Arabic structure of onset may be represented as (C) (C) CV. Therefore, initial consonant cluster in word- initial position is allowed in Ammani Arabic with very few restrictions as in words like /traab / 'soil' and /kfu:f/ 'gloves'. Ammani Arabic allows complex onsets regardless of whether the consonant cluster obeys or flouts the SSP. For instance, the consonantal sequence in the word /traab/ 'soil' obeys the SSP. In contrast, the consonantal sequence in / $\mathrm{kfu}: \mathrm{f} /$ 'gloves' violates the SSP and such sequence exists in Ammani Arabic.

Watson (2002) suggested that the violation that appears in /kfu:f/ 'gloves' is an example of 'reversal', in which a high sonorant sound is followed by a less sonorant one. Her study suggested another type of violation -'plateaux', in which the cluster is formed of two segments with the same value of sonority. This is illustrated by /kta:b/ 'book'. In /kta:b/, an obstruent is followed by another obstruent. Based on what has been said, an initial consonant cluster does exist in Ammani Arabic no matter what sonority the resulting adjacent consonants have. Even onsets with three consonants are allowed in Ammani Arabic. In such a case, the first two consonants have to be a geminate and the third one has to be of a rising sonority, which can be illustrated by /sswadd/ 'blackened'. To recapitulate, onsets are obligatory segments in Ammani Arabic syllables. Regardless of the sonority status of the segments, onset clusters in word-initial position are allowed.

\subsection{Problem Statement \& Significance of the Study}

None of the research has investigated the development of word-initial cluster in the speech of a bilingual child, whose two first languages are Arabic and English. Therefore, the main goal of this study is to provide a comparative description of the developmental path of English and Arabic consonantal sequences word-initially. It also describes the repair strategies used by the bilingual child to simplify the clusters in both languages. The study has significantly contributed to the literature of the acquisition of consonant cluster in general. It has also formed a threshold for future research on the acquisition of consonant cluster in onset position of 'two first languages' one of which is Arabic in particular

\subsection{Hypotheses}

In light of the differences between the typologies of English and Arabic and in light of the circumstances through which the child experienced acquiring both languages, the following hypotheses have been drawn:

1. The child would produce English target clusters before Arabic clusters, since the bilingual child's dominant language was English, rather than Arabic.

2. The most marked Arabic cluster (reversal) is acquired after core and plateaux onset clusters.

3. The subject uses the same strategies to repair branching onsets in English and Arabic. 


\section{Related Studies}

The acquisition of consonant clusters has been the target of a large amount of research in English (Kirk and Demuth, 2005; Pater and J Barlow, 2003; Stites et al., 2004; Templin, 1957), in Dutch (Levelt et al., 2000), and in German and Spanish (Lleo and Prinz, 1996).

In their investigation of the assumption that children's selection of a particular segment of a cluster and their deletion of the other depends on universal conditions of feature markedness or sonority, LIeo and Prinz (1996) found essential differences between the German and the Spanish data. German children tended to retain the first consonant $\mathrm{C} 1$; while, Spanish children tended to retain the second consonant $\mathrm{C} 2$, regardless of the sonority of the segments. The decision on which consonant to retain in the clusters by German and Spanish children was dictated by the specific directionality parameters in the two languages.

Pater and Barlow's (2003) analysis accounted for the divergence shown in the production of some children that would lead to deviation from what is considered a universal pattern. The universal scale of the preferred onset cluster in light of the sonority of its segments is reflected in the terms of factorial typology along with its outputs. There were cases in which the segments with the higher sonority were kept and the ones with lower sonority were deleted. This indicated that deviation from the sonority pattern was possible. For instance, it was illustrated that a child might produce /nou/ for the word 'snow', even though, the word /sou/ was expected to survive rather than /nou/, in light of the sonority pattern. They attributed this variety of production to the ranking of constraints within the framework of Optimality Theory.

Daana (2009) investigated the acquisition of consonant cluster in onset position in a form of Jordanian Arabic. The findings showed that several factors determined the earlier acquisition of some particular sequences as compared to the others. Sonority distance, ease of articulation, frequency in the input, and salient perception of the sequences were the factors that played vital roles in deciding which sequence was to be acquired before the other sequences.

\section{Materials and Methods}

\subsection{Data Collection}

No corpora of Arabic is available through any sort of electronic database. On the contrary, large amount of corpora of child production of English collected through regular periodic observation was made accessible to researchers through CHILDES. Therefore, by virtue of the lack of Arabic electronic database, the first researcher has decided to collect data from her own child. The source of data tackled in this study is the recording sessions of spontaneous and non-spontaneous speech between the first researcher and her bilingual child.

The child of the first researcher was born in the UK and was exposed to British English for seven to eight hours every day as he was sent to a university day-care nursery. Later, the child was sent to a British Nursery close to the child's residency in the UK. Arabic-Ammani Arabic- was the native language of the child's parents and was mainly used by the child's father. The child's mother used to speak to her child in both languages. The dominant language of the child was English, although the child was exposed to two languages since his birth. The child preferred using English, rather than using Arabic because the child had spent longer time in the nursery than his home. Therefore, the child was exposed to English more than Arabic. Lieven (2010) discussed the preference of a language over the other by bilingual children. Lieven's study showed that bilingual children may have relatively full competence of both languages; however, variability was expected in their production.

The first author, the child's mother, was a $\mathrm{PhD}$ student majoring in Language Acquisition at that time. The researcher and her child spent a long time distributed over different sessions on daily basis talking, playing, arguing, describing pictures, telling stories, and reading stories in both languages. Each session lasted for 45 minutes every day and were audio taped using a Panasonic RX-M70M3 device. Sessions took place at home either in the living room or in the child's room and nobody was present with the researcher and the child when the recordings were being done.

Being a professional phonetician, all the recordings were narrowly transcribed by the first researcher and were checked by another potential PhD Jordanian student who was majoring in Phonology. The utterances of the child were transcribed by the first researcher using broad Charis SIL IPA fonts. The transcribed utterances were classified by language and age; for instance, E 1; 04 indicated English production at the age of one year and four months. The data was saved in computer files. Each file included the transcription of the child's utterance, the transcription of the adult-equivalent, the word in orthography, number of times the utterance was repeated, and other details about the context if necessary. In case of the Arabic data, the glossary of the Arabic words was also given. 
For the purpose of this study, the researchers analyzed the child's production when he first started repairing target word-initial cluster at the age of 1;04. His production before 1; 04 was mainly formed of CV in English and Arabic, CVC in English and Arabic and VC in English without any trace of an utterance that had target or repaired clusters. The child started producing two-word utterances at around the age of two. The first researcher conducted interval and formal experiments along with the spontaneous and non-spontaneous recording sessions to neutralize the impact of connected speech on the production of word-initial consonant clusters. The formal experiments were conducted in different forms. For instance, the researcher showed the subject pictures of things and asked the subject to name them. Moreover, the researcher pointed at different objects and asked the child to name them. The researcher would ask him to repeat that word in isolation if the child produced a word with the target cluster accompanied by other words or sounds to double check the production of the target cluster.

\section{Results and Discussion}

The child started producing meaningful sounds at the age of 7 months. However, the child produced CV structure in both English and Arabic at a later age. This was followed by the production of CVC in English and Arabic, and VC in English. At the age of 1;04, the first target word-initial cluster was repaired and at the age of 1;09 the subject started repairing the word-initial cluster constantly. Therefore, data collected before 1;04 was neglected. At the age of $1 ; 04$, the child produced only one target word-initial cluster that was reduced to a singleton. By the age of $1 ; 09$, all target word-initial clusters were truncated into singletons. It was not until the age of 2;05 when the child's repair strategies started to vary. The different productions of the same word varied between the production of the word deleting one segment, for instance, [fawa] flower and the insertion of an epenthetic vowel as in [fawawa] flower. In very few cases, the child replaced one segment of the cluster with another one as in [nju:zik] music.

The sessions examined were grouped into one-year intervals according to the child's age to avoid sparse data effects. The first stage covered the ages between 1;04 and 2;04; while, the second stage covered the ages between 2;05 and $3 ; 05$. The last stage covered the ages between 3;06 and 4;06. If a particular sequence in onset position occurred in different words, and if each word was produced at least four times within the same age-stage, the cluster was considered acquired. It was not until around the age of 4;06 that the target words-words with initial consonant clusters- were almost faithful to the input except for the replacement of the liquid sounds with glides.

\subsection{Stage One}

Stage 1 depicts that the child's first repair strategy of word-initial cluster was being noticed at the age of 1;04. The target words with clusters in onset position were produced with singletons between the ages of 1;04 and 2;04. The very first and only target word produced at the age of 1;04 was the English word three which was produced as [?i:] while trying to count with a cartoon character on the television. The child's production at this age was CV or a reduplicated $\mathrm{CV}$ with consonants such as $/ \mathrm{m}, \mathrm{n}, \mathrm{t}, \mathrm{t}, \mathrm{l}, \mathrm{k}, \mathrm{b}, \mathrm{p} /$ in the onset position. It is not easy to decide whether the glottal / $/$ / corresponds specifically to the interdental fricative or the liquid since no fricative was produced as an onset of any of the child's words at this age and the child's data at this age lacked the production of any liquid. The only clear assumption that can be made is that the child had truncated the cluster into a singleton.

At the age of 1;09 (5 months later), English three was produced as [fi:]. Other English target words with word-initial clusters formed of a stop or a fricative followed by a liquid (core cluster) emerged in the child's production and underwent the deletion of the liquid. In other words, the child deleted the right edge consonant in light of the SSP. Arabic with such target sequence in onset position appeared remarkably later at the age of 2;03. The child chose to delete the liquid- the right edge consonant in Arabic also in light of the SSP. This is exemplified in table 1. 
Table 1. a fricative/a stop + a liquid

\begin{tabular}{|c|c|c|c|c|c|}
\hline \multirow[t]{2}{*}{ Age } & \multicolumn{2}{|l|}{ English } & \multicolumn{3}{|l|}{ Arabic } \\
\hline & Target words & Child's production & Target words & $\begin{array}{l}\text { Child's } \\
\text { production }\end{array}$ & Glossary \\
\hline $1 ; 09$ & flower & [favə] & & & \\
\hline $1 ; 10$ & floor & [fo:] & & & \\
\hline \multirow[t]{4}{*}{2} & tree & [ti:] & & & \\
\hline & green & [gi:n] & & & \\
\hline & triangle & [trkaka] & & & \\
\hline & blue & [bu:] & & & \\
\hline $2 ; 01$ & please & [pi:s] & & & \\
\hline \multirow[t]{8}{*}{$2 ; 03$} & frog & [fog] & & & \\
\hline & front & [font] & & & \\
\hline & fly & [far] & /Sri:t/ & [Si:t] & cassette \\
\hline & flag & [fæg] & /Sribıt/ & [SIbIt $]$ & I drank \\
\hline & drop & [d॰p] & & & \\
\hline & drum & {$[\mathrm{d} \Lambda \mathrm{m}]$} & & & \\
\hline & train & [tern] & /tre:n/ & [te:n] & train \\
\hline & & & /trena:t/ & [tena:t] & trains \\
\hline \multirow[t]{10}{*}{$2 ; 04$} & fruit & [fu:t] & /hra:m/ & [ha:m] & blanket \\
\hline & slow & [səu] & /zla:m/ & [za:m] & men \\
\hline & sleep & [si:p] & & & \\
\hline & clean & [ki:n] & /bwa:ț/ & [ba:t] & boots \\
\hline & & & /bwa:b/ & [ba:b] & doors \\
\hline & press & [pes] & /kla:b/ & [ka:b] & $\operatorname{dog} s$ \\
\hline & cry & [kaI] & /tra:b/ & [ta:b] & soil \\
\hline & black & [bæk] & & & \\
\hline & bridge & [bIdz] & & & \\
\hline & brown & [baun] & & & \\
\hline
\end{tabular}

At the age of 2 years, the English clusters formed of a fricative followed by a nasal occurred. The subject chose to delete the fricative (the left edge consonant) and retain the nasal, which shows a deviation from the SSP. This production was supportive evidence of Pater and Barlow's (2003) findings. The Arabic similar sequence, on the other hand, was repaired by inserting an epenthetic vowel as in [Yamaja] for 'you do it' and [zama:j] for /3ma:1/ 'camels' (Table 2).

Table 2. a fricative + a nasal

\begin{tabular}{llllll}
\hline Age & English & & Arabic & \\
\cline { 2 - 5 } & Target & Child's & Target & Child's \\
word & Production & Production & \\
\hline 2 & snow & {$[$ nov $]$} & & & \\
$2 ; 03$ & small & [mo:j] & /Smalha/ & [Yamaja] & you do it \\
$2 ; 04$ & & & /3ma:1/ & [zama:j] & camels \\
\hline
\end{tabular}

However, in onset clusters formed of fricatives followed by stops, a discrepancy in the child's repaired strategies was detected in both languages. English left-edge fricatives which had higher sonority than the stops were deleted. On the 
other hand, the Arabic fricatives were retained and the Arabic right-edge stops were deleted except for the Arabic word /ftu:r/ 'breakfast'. The child chose to delete the fricative and retain the stop. The production of this type of cluster is exemplified in table 3.

Table 3. a fricative + a stop

\begin{tabular}{|c|c|c|c|c|c|}
\hline \multirow[t]{3}{*}{ Age } & \multicolumn{2}{|c|}{ English } & \multicolumn{3}{|l|}{ Arabic } \\
\hline & Target & Child's & Target & Child's & Glossary \\
\hline & words & production & words & production & \\
\hline \multirow[t]{2}{*}{$1 ; 10$} & sky & [kaI] & & & \\
\hline & spoon & [pu:n] & & & \\
\hline \multirow[t]{2}{*}{2} & star & [ta:] & & & \\
\hline & space & [pers] & & & \\
\hline $2 ; 01$ & school & [ku:] & & & \\
\hline $2 ; 02$ & spider & [paidə] & & & \\
\hline $2 ; 03$ & speak & [pi:k] & & & \\
\hline \multirow[t]{4}{*}{$2 ; 04$} & stop & [top] & /stanna/ & [sanna] & wait (M) \\
\hline & story & [to:ji:] & /stanni/ & [sanni] & wait $(F)$ \\
\hline & scooter & [ku:tə] & /Stare:tha/ & [Saje:ta] & I bought it $(\mathrm{F})$ \\
\hline & & & /fțu:r/ & [tu:j] & breakfast \\
\hline
\end{tabular}

The English clusters in which the second segment is a glide were truncated by deleting the glide- right edge consonant- by virtue of its higher sonority as compared to the sonority of the first segment. Only three of such a target cluster emerged and no Arabic words with such cluster emerged at this stage (Table 4).

Table 4. A nasal/stop + a glide

\begin{tabular}{|c|c|c|c|c|c|}
\hline \multirow[t]{3}{*}{ Age } & \multicolumn{2}{|l|}{ English } & \multicolumn{3}{|l|}{ Arabic } \\
\hline & Target & Child's & Target & Child's & Glossary \\
\hline & words & Production & words & production & \\
\hline $2 ; 03$ & twinkle & [tıjku] & & & \\
\hline \multirow[t]{2}{*}{$2 ; 04$} & news & [nu:z] & & & \\
\hline & music & [nu:zık] [mu:zık] & & & \\
\hline
\end{tabular}

Other types of Arabic consonantal sequences that had no English resemblance were truncated into singletons. The first Arabic sequence was composed of a nasal followed by a stop- reversal cluster- and the sequence was repaired by deleting the left- edge nasal complying with the SSP (Table 5).

Table 5. a nasal + a stop

\begin{tabular}{llll}
\hline Age & Arabic & & Glossary \\
\cline { 2 - 4 } & Target & Child's & \\
\hline $2 ; 03$ & words & Production & it broke (F) \\
& /nkasrat/ & [kassat] & it broke (M) \\
$2 ; 04$ & /nkasar/ & {$[$ kasaj] } & a pair of scissors \\
\hline
\end{tabular}

An Arabic stop followed by a fricative was truncated by deleting the left -edge stop that had possessed lower sonority violating the SSP. This is shown in table 6. 
Table 6. a stop + a fricative

\begin{tabular}{llll}
\hline Age & Arabic & & Glossary \\
\cline { 2 - 4 } & Target & Child's & \\
& words & Production & \\
\hline $2 ; 03$ & $/$ tfaddal/ & [faddaj] & come in \\
& /kfu:f/ & [fu:f] & gloves \\
\hline
\end{tabular}

An Arabic cluster formed of a liquid followed by a fricative was repaired by deleting the left edge liquid complying with the SSP (Table 7).

Table 7. a liquid + a fricative

\begin{tabular}{llll}
\hline Age & Arabic & & Glossary \\
\cline { 2 - 4 } & Target & Child's & \\
& words & Production & come in \\
& $/$ rfu:f/ & {$[$ fu:f] } & I played \\
\hline
\end{tabular}

The child's choice to reduce the branching onsets in both languages asserted the fact observed by Fikkert (1994). Fikkert's study suggested stages for the acquisition of onset clusters based on the Dutch data. It was assumed that the first stage is 'Stage 0' through which branching onsets is not represented in the data of children (Fikker, 1994). In the present study, the branching onsets were not represented in the child's production at this stage. The presented data showed inconsistency in the child's deletion of one segment from the branching onset. At times, the child chose to reduce the cluster to its left-edge segment $\mathrm{C} 1 \mathrm{C} 2 \rightarrow \mathrm{C} 1 \varnothing$ and sometimes chose to reduce the branching onset to its right-edge element $\mathrm{C} 1 \mathrm{C} 2 \rightarrow \varnothing \mathrm{C} 1$. The child complied with the SSP and the Universal Onset Hierarchy proposed by Clements (1990) while handling some types of cluster. However, the child's production reflects deviation from this hierarchy while handling other types. The child's sonority pattern of his cluster reduction can be illustrated as follows:

- $\quad \mathrm{C} 1 \mathrm{C} 2 \rightarrow \mathrm{C} 1 \varnothing$ where $\mathrm{C} 1$ is a fricative/a stop and $\mathrm{C} 2$ is a liquid in English and Arabic.

- $\mathrm{C} 1 \mathrm{C} 2 \rightarrow \mathrm{C} 1 \varnothing$ where $\mathrm{C} 1$ is a nasal and $\mathrm{C} 2$ is a glide in English.

- $\mathrm{C} 1 \mathrm{C} 2 \rightarrow \varnothing \mathrm{C} 2$ where $\mathrm{C} 1$ is a fricative and $\mathrm{C} 2$ is a stop in English.

- $\mathrm{C} 1 \mathrm{C} 2 \rightarrow \varnothing \mathrm{C} 2$ where $\mathrm{C} 1$ is a nasal and $\mathrm{C} 2$ is a fricative in Arabic.

- $\mathrm{C} 1 \mathrm{C} 2 \rightarrow \varnothing \mathrm{C} 2$ where $\mathrm{C} 1$ is a liquid and $\mathrm{C} 2$ is a fricative in Arabic.

It can be inferred from the illustration that the segment with higher sonority was deleted whether it was on the right edge or the left edge of the cluster. This abidance applied to both languages. On the other hand, the child's conformity with the SSP and the Universal Onset Hierarchy was inconsistent in some other types of cluster. This inconsistency was evidenced in the child's production of English branching onsets composed of fricatives and nasals. It is also evidenced in the production of Arabic branching onsets composed of fricatives and stops. The child's counter sonority- pattern reduction can be summarized as follows;

- $\mathrm{C} 1 \mathrm{C} 2 \rightarrow \varnothing \mathrm{C} 2$ where $\mathrm{C} 1$ is a fricative and $\mathrm{C} 2$ is a nasal in English.

- $\mathrm{C} 1 \mathrm{C} 2 \rightarrow \varnothing \mathrm{C} 2$ where $\mathrm{C} 1$ is a stop and $\mathrm{C} 2$ is a fricative in Arabic.

- $\mathrm{C} 1 \mathrm{C} 2 \rightarrow \mathrm{C} 1 \varnothing$ where $\mathrm{C} 1$ is a fricative and $\mathrm{C} 2$ is a stop in Arabic.

As a matter of fact, $\mathrm{C} 1 \mathrm{C} 2 \rightarrow \mathrm{C} 1 \varnothing$, where $\mathrm{C} 1$ is a fricative and $\mathrm{C} 2$ is a stop in Arabic, was also reduced to its right edge element in very few cases;

- $\mathrm{C} 1 \mathrm{C} 2 \rightarrow \varnothing \mathrm{C} 2$ where $\mathrm{C} 1$ is a fricative and $\mathrm{C} 2$ is a stop in Arabic.

The truncation of branching onsets whether to the right or the left edge element was attested in the acquisition of other languages (Fikkert, 1994; Freitas, 2003; Gnanadesikan, 1995; Lleo, 1990; Lleo and Prinz, 1996; Rose, 2000).

Furthermore, the divergence shown in the child's production which had led to a deviation from the universal pattern was attested by Pater and Barlow (2003). Although the child's production reflected the universal scale of the preferred onset cluster in terms of the sonority of its segments to a large extent, there were cases in which his production did not reflect this universal scale. The following data sets provide examples of the child's tendency of 
conforming to the SSP and in other cases deviating from it. They also compare this varied tendency with other children's production in previous research. The first data set shows examples of sonority pattern reduction from English (Gnanadesikan 2003 reanalysed by Pater and Barlow 2003: 488). It also shows examples from Portuguese (Freitas 2003) and from Ammani Arabic (Daana 2009).

Data Set 1. Sonority Pattern Reduction in this Study and other Related Studies

\begin{tabular}{|c|c|}
\hline \multicolumn{2}{|c|}{ English (Pater and Barlow) } \\
\hline Child's Production & Target Form \\
\hline [biw] & spill \\
\hline [ki:n] & clean \\
\hline [pi:z] & please \\
\hline \multicolumn{2}{|c|}{ Portuguese (Freitas) } \\
\hline [bánku] & branco \\
\hline [pedju] & predio \\
\hline [brasu] & braço \\
\hline \multicolumn{2}{|c|}{ Ammani Arabic (Daana) } \\
\hline [?ass $]$ & /miașs/ \\
\hline [ka:b] & /klaa:b/ \\
\hline [tu:f] & /kfu:f/ \\
\hline \multicolumn{2}{|c|}{ English (this subject) } \\
\hline [ki:n] & clean \\
\hline [pi:s] & please \\
\hline [dəp] & drop \\
\hline \multicolumn{2}{|c|}{ Arabic (this subject) } \\
\hline [ha:m] & /hra:m/ \\
\hline$[\mathrm{ka}: \mathrm{b}]$ & /kla:b/ \\
\hline [ji:t] & / rri:t/ \\
\hline
\end{tabular}

The second data set, however, shows examples of counter sonority pattern reduction from English (Pater and Barlow 2003:488) and from Ammani Arabic (Daana 2009).

Data Set 2. Counter Sonority Pattern Reduction in this Study and other Related Studies

$\begin{array}{ll}\text { English (Pater and Barlow) } \\ \text { Child's Production } & \text { Target Form } \\ \text { [næ] } & \text { snap } \\ \text { [ni:z] } & \text { sneeze }\end{array}$

Ammani Arabic (Daana)

[lu:f] /rfu:f/
[la:je] /mra:je/
English (this subject)
[nəu] snow
[mə:j] small
Arabic (this subject)
[sanna] /stanna/
[fad̦diaj]

Epenthesis as a repair strategy was used only once when the child chose to epenthesize a short front vowel to break the cluster which was formed of a fricative followed by a nasal $(\mathrm{C} 1 \mathrm{C} 2 \rightarrow \mathrm{C} 1 \mathrm{VC} 2)$. This epenthesis process was applied once at this stage; therefore, it was ignored. 


\subsection{Stage Two}

At stage two, the child started to produce more target words with initial clusters at around the age of 2;05. At this age- stage the subject showed other repair strategies. He resorted to epenthesis and prothesis- inserting a complete syllable /RI/, along with seldom truncation of the cluster. Epenthesis was used to repair both English and Arabic clusters; while, prothesis was used to repair Arabic clusters only. In very few cases, the child's production was faithful to the input; that is both elements of the English and Arabic clusters were clearly articulated. This variation took place between the ages of 2;05 and 3;05.

Table 8. a fricative /a stop+ a liquid

\begin{tabular}{|c|c|c|c|c|c|}
\hline \multirow[t]{2}{*}{ Age } & \multicolumn{2}{|l|}{ English } & \multicolumn{3}{|l|}{ Arabic } \\
\hline & $\begin{array}{l}\text { Target } \\
\text { words }\end{array}$ & $\begin{array}{l}\text { Child's } \\
\text { productions }\end{array}$ & $\begin{array}{l}\text { Target } \\
\text { words }\end{array}$ & $\begin{array}{l}\text { Child's } \\
\text { production }\end{array}$ & Glossary \\
\hline $2 ; 05$ & $\begin{array}{l}\text { three } \\
\text { throw } \\
\text { flower } \\
\text { floor } \\
\text { grey }\end{array}$ & 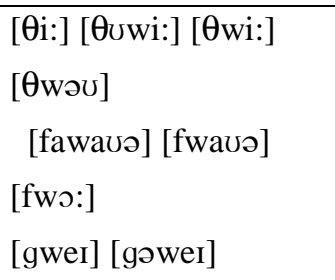 & & & \\
\hline $2 ; 06$ & fruit & [fowu:t] & /treIn/ & [te:n] & train \\
\hline $2 ; 07$ & green & [gi:n][gwi:n] & & & \\
\hline $2 ; 09$ & blue & [bwu:] [bəwu:] [bu:] & & & \\
\hline \multirow[t]{4}{*}{$3 ; 01$} & $\begin{array}{l}\text { frog } \\
\text { Friday }\end{array}$ & $\begin{array}{l}\text { [fwog] } \\
\text { [fwarder] }\end{array}$ & /trein/ & [trje:n] & train \\
\hline & tree & [ti:] [twi:] [tri:] & /tra:b/ & [tta:b] [tja:b] [?ttja:b] & soil \\
\hline & cry & [kwaI] [kraI] & /tru:h/ & [ju:h] [tju:h] & you will go \\
\hline & & & /kla:b/ & [ka:b] & \\
\hline \multirow[t]{9}{*}{$3 ; 03$} & train & [tern] [twein][/treIn] & /kla:b/ & [kija:b] & dogs \\
\hline & grass & [gwa:s] & & & \\
\hline & sly & [swar] & & & \\
\hline & slowly & [swəuji] & & & \\
\hline & slide & [swaI] & & & \\
\hline & play & [pjer] [pleı] & & & \\
\hline & drink & [dınk] [dwınk] [drınk] & & & \\
\hline & clean & [kji:n] & & & \\
\hline & promise & [pwomis] & & & \\
\hline \multirow[t]{4}{*}{$3 ; 04$} & sleep & [si:p] [sji:p] & /hra:m/ & [hja:m] [?hja:m] & blanket \\
\hline & & & / $\mathrm{fribit} /$ & [Sibit] [Sjibit] & I drank \\
\hline & black & [bæk] [bjæk/][blæk] & /kla:b/ & [kija:b][/kja:b] & dogs \\
\hline & brought & [bwo:t] [bro:t] & /dmu:Yi/ & [mu:Pi] & my tears \\
\hline \multirow[t]{4}{*}{$3 ; 05$} & fridge & [fwedz] & /Sri:t/ & 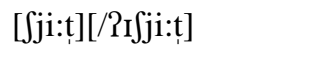 & cassette \\
\hline & front & [font] [fwont] & /Ila:m/ & [?:m] [?ja:m] & flags \\
\hline & friend & [fwend] [fend] & /zla:m/ & [zja:m] & men \\
\hline & clock & [kwok] & /Rru:d/ & [?iju:d] & monkeys \\
\hline
\end{tabular}


Table 8 shows a delay in the production of Arabic target cluster compared to the early production of English cluster. It also depicts that there are very few cases of faithful production. The table also shows the child's choice of inserting an epenthetic vowel to break both English and Arabic clusters. However, prothesis-inserting /RI/- was occasionally used to break Arabic clusters only. Geminate was used only once to break the /tr/ sequence in /tra:b/ soil which was produced as [tta:b]. The use of geminates as a repair strategy has not been attested in the acquisition of other languages; however, it was used by Daana's subjects acquiring Ammani Arabic (2009).

In addition, the data in table 8 reveals that the liquid occurred in the child's production was almost always replaced by a glide. English liquid, /r/ was replaced by [w] and the Arabic/r/ was replaced by [j]. The reason why English /r/ was replaced by [w] can be attributed to the effect of the [+rounded] feature enjoyed by English /r/. It is clear that the bilingual child was aware of the roundness of the English $/ \mathrm{r} /$ and replaced it with [w] accordingly. However, Arabic $/ \mathrm{r} /$, does not carry such a feature; therefore, the child constantly replaced it with [j]. The child was consistent producing Arabic /r/ as [j] in Arabic words with singleton /r/ in onset position as in [ju:h] 'you go away'. Even in coda singleton, Arabic /r/ was replaced by [j] as in [hama:j] instead of /hma:r/ 'donkey'. The child was also consistent replacing English /r/ with [w] in words that possess singleton $/ \mathrm{r} /$ as in [w $\mathrm{wn}$ ] for run. This sort of replacement depicts that bilingual children are usually aware of the phonotactics of both languages that are acquired by them and their production reflects this awareness.

Mostly, the child replaced the English liquid /// with a glide and this replacement of English /1/ varied between [j] and $[w]$. Scrutinizing the cases in which /// was replaced by [j] and [w], English data set provides us with examples of regressive harmony where a feature of the vowel is extended to the preceding consonant. Long /i:/ in sleep and short /i/ at the end of slowly are front and high. This results in the production of the word as [sj:p] and [swavji] respectively extending the feature [high] of the vowel to the preceding segment changing it from $/ \mathrm{l} / \mathrm{into}[\mathrm{j}]$. On the contrary, when /1/ occurs before back and low vowels as in slide, slowly, and floor the child tried to extend this back feature of the vowels /a/, /əo/ and /o:/, in the respective order, resulting in changing the /l/ into the labeo-velar [w]. As far as Arabic /1/ is concerned, it cannot be suggested that this regressive harmony applied to Arabic /1/ which was replaced by [j].The fact that such a sequence appeared only in one Arabic word /kla:b/ 'dogs', which was pronounced as [kja:b] makes it insufficient to receive further elaboration.

It is worth pointing out that the subject produced English /// as [w] before back vowels in words with singletons as in [wok] for look. /l/ was replaced with [j] when followed by a front vowel such as [jet] for let. /l/ in singleton codas was always velarized and was replaced by $/ \mho /$ as in [œpu] for apple. The replacement of liquids with glides can be attributed to the difficulty of the production of the liquids compared to the other sounds. Brown (2015) assumed that the difficulty of the production of liquids compared to all other segments made them acquired late. Brown suggested that they are produced well after the age of 5 years (Brown, 2015). Daana (2009) found out that her subjects acquired the Arabic liquids as late as 5 years of age. Al Amayreh (1996) claimed that Jordanian liquids were acquired at the age of 6 years.

The child sometimes inserted an epenthetic vowel and at other times produced the cluster faithfully when clusters with fricatives and nasals were concerned (Table 9).

Table 9. a fricative + a nasal

\begin{tabular}{|c|c|c|c|c|c|}
\hline \multirow[t]{2}{*}{ Age } & \multicolumn{2}{|l|}{ English } & \multicolumn{3}{|l|}{ Arabic } \\
\hline & $\begin{array}{l}\text { Target } \\
\text { words }\end{array}$ & $\begin{array}{l}\text { Child's } \\
\text { production }\end{array}$ & $\begin{array}{l}\text { Target } \\
\text { words }\end{array}$ & $\begin{array}{l}\text { Child's } \\
\text { production }\end{array}$ & Glossary \\
\hline $2 ; 05$ & $\begin{array}{l}\text { snake } \\
\text { small }\end{array}$ & $\begin{array}{l}\text { [səneIk] } \\
\text { [səməj] }\end{array}$ & & & \\
\hline $\begin{array}{l}2 ; 07 \\
2 ; 10\end{array}$ & $\begin{array}{l}\text { snow } \\
\text { small }\end{array}$ & $\begin{array}{l}\text { [sənəu] [snəu] } \\
\text { [sm॰:j] }\end{array}$ & /Smeltha/ & [?imejetta] & I did it \\
\hline $3 ; 01$ & & & /hma:r/ & [hama:j] & donkey \\
\hline $3 ; 05$ & smooth & [səmu:ð] [smu:ð] & $\begin{array}{l}\text { /sna:n/ } \\
\text { /Smu:s/ } \\
\text { /3ma:1/ }\end{array}$ & 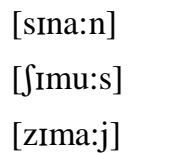 & $\begin{array}{l}\text { teeth } \\
\text { suns } \\
\text { camels }\end{array}$ \\
\hline
\end{tabular}


In addition to the child's production of the English clusters properly, the child chose to epenthesize a vowel on some occasions. Whereas; in Arabic, the repair strategies varied between prothesis and epenthesis. Moreover, no faithful production of such a sequence was produced in Arabic.

The only fricative that occurred in the sequence fricative+stop was $/ \mathrm{s} /$ in the child's English data. Whereas, the fricative in the Arabic sequences varied between $/ \mathrm{f} /, / \mathrm{s} /, / 3 /$, and $/ \mathrm{S} /$ at this age-stage. In addition to the child's proper production of this sequence in both languages, there were occasional instances of deleting one segment. The child was consistent in deleting the /s/ sound and retaining the stop in English. However, this consistency was not detected in the child's Arabic production. The child's strategy alternated between deleting the fricative and deleting the stop. Epenthetic vowel was not used to break this form of cluster in English. Epenthesis, prothesis, and occasional proper production was used for such a cluster in Arabic (Table 10).

Table 10. a fricative + a stop

\begin{tabular}{|c|c|c|c|c|c|}
\hline \multirow[t]{2}{*}{ Age } & \multicolumn{2}{|c|}{ English } & \multicolumn{3}{|l|}{ Arabic } \\
\hline & $\begin{array}{l}\text { Target } \\
\text { words }\end{array}$ & $\begin{array}{l}\text { Child's } \\
\text { production }\end{array}$ & $\begin{array}{l}\text { Target } \\
\text { words }\end{array}$ & $\begin{array}{l}\text { Child's } \\
\text { production }\end{array}$ & Glossary \\
\hline $2 ; 07$ & spoon & [spu:n] & /Stare:tha/ & [Saje:tha] & I bought it $(\mathrm{F})$ \\
\hline $2 ; 10$ & story & [to:ji] [sto:ji] & /Stare:tha/ & [?I taje:tha] & I bought it $(\mathrm{F})$ \\
\hline $3 ; 01$ & $\begin{array}{l}\text { spider } \\
\text { sky } \\
\text { star } \\
\text { stop } \\
\text { start }\end{array}$ & $\begin{array}{l}\text { [pardə] [spaidə] } \\
\text { [kaI] [skaI] } \\
\text { [ta:] [sta:] } \\
\text { [stəp] } \\
\text { [sta:t] }\end{array}$ & /Stare:tha/ & [Staje:tha] & I bought it (F) \\
\hline $3 ; 02$ & speak & [pi:k] [spi:k] & /ftu:r/ & [futu:j] [ftu:j] & breakfast \\
\hline $3 ; 03$ & $\begin{array}{l}\text { space } \\
\text { stuck }\end{array}$ & $\begin{array}{l}\text { [spers] } \\
{[\mathrm{st} \Lambda \mathrm{k}]}\end{array}$ & $\begin{array}{l}\text { /staimal/ } \\
\text { /3ba:1/ }\end{array}$ & $\begin{array}{l}\text { [stamaj] } \\
\text { [ziba:j] [?Izba:j] }\end{array}$ & $\begin{array}{l}\text { he used } \\
\text { mountains }\end{array}$ \\
\hline
\end{tabular}

The child's English data contained the following when the clusters were formed of nasals followed by glides (Table 11).

Table 11. a nasal + a glide

\begin{tabular}{llllll}
\hline Age & English & & Arabic & \\
& \cline { 2 - 5 } & Target & Child's & Glossary \\
& words & production & $\begin{array}{l}\text { Target } \\
\text { words }\end{array}$ & $\begin{array}{l}\text { Child's } \\
\text { production }\end{array}$ & \\
\hline $2 ; 10$ & new & [nju:] & & \\
$3 ; 02$ & news & [nju:z] & & \\
$3 ; 03$ & music & [nju:zik] [mju:zik] & & \\
\hline
\end{tabular}

The child had no problem with this sort of cluster, except for the occasional replacement of $/ \mathrm{m} / \mathrm{with}[\mathrm{n}]$ in music. However, the Arabic data lacked such a sequence.

The other types of Arabic consonantal sequences that do not exist in English witnessed less truncation, more faithfulness, more epenthesis, and more prothesis. The first such Arabic sequences composed of a nasal followed by a stop was repaired by deleting the left- edge nasal, epenthesizing a vowel, and prothesis. However, the sequence matched the input occasionally (Table 12). 
Table 12. a nasal + a stop

\begin{tabular}{|c|c|c|c|}
\hline \multirow[t]{3}{*}{ Age } & \multicolumn{2}{|l|}{ Arabic } & \multirow[t]{3}{*}{ Glossary } \\
\hline & Target & Child's & \\
\hline & words & Production & \\
\hline \multirow[t]{2}{*}{$2 ; 06$} & /nkasrat/ & [nkasjat] & it broke $(\mathrm{F})$ \\
\hline & /nkasar/ & [kasaj] & it broke (M) \\
\hline \multirow[t]{2}{*}{$2 ; 07$} & /miașs/ & [?așs ] [maPașs] & a pair of scissors \\
\hline & & [mi niasss] & \\
\hline $2 ; 08$ & /mba:reh/ & [ba:jeћ] & yesterday \\
\hline $2 ; 09$ & /mba:reh/ & [nba:jeh][?Imba:jeh] & yesterday \\
\hline \multirow[t]{2}{*}{$3 ; 01$} & /mba:reh/ & [mba:reh] & yesterday \\
\hline & /miass/ & [?In?așs] & a pair of scissors \\
\hline
\end{tabular}

No changes in the repair strategy used to produce the Arabic sequence formed of a stop followed by a fricative was witnessed. Such a sequence was always truncated by deleting the left -edge stop and retaining the fricative. The production of this sequence is exemplified in table 13.

Table 13. a stop + a fricative

\begin{tabular}{llll}
\hline Age & Arabic & & Glossary \\
\cline { 2 - 4 } & Target & Child's & \\
& words & Production & come in \\
\hline $2 ; 07$ & $/$ tfaddal/ & {$[$ faddaj] } & gloves \\
$3 ; 04$ & $/$ kfu:f/ & {$[$ fu:f] } & you enter \\
& /tfu:t/ & {$[$ fu:t] } & \\
\hline
\end{tabular}

This could be attributed to the difficulty in the production of such a sequence (James et al., 2000; Lieven, 2010). However, it can also be attributed to the difficulty in the perception of such a sequence (Bladon, 1986; Daana, 2009; James et al., 2000;Jun, 2004; Manuel, 1991; Ohala, 1990; Wright, 2004).

An Arabic liquid followed by a fricative was repaired by deleting the left-edge liquid, epenthesizing a vowel to break the cluster, and inserting / $\mathrm{I} /$-prothesis. Such a reversal cluster sequence was not produced properly at this age (Table 14).

Table 14. a liquid + a fricative

\begin{tabular}{|c|c|c|c|}
\hline \multirow[t]{3}{*}{ Age } & \multicolumn{2}{|l|}{ Arabic } & \multirow[t]{3}{*}{ Glossary } \\
\hline & Target & Child's & \\
\hline & words & Production & \\
\hline $3 ; 02$ & /rfu:f/ & [fu:f][/jufu:f] & shelves \\
\hline $3 ; 03$ & /rfu:f/ & [?ijfu:f] & shelves \\
\hline \multirow[t]{2}{*}{$3 ; 04$} & /lisibit/ & [Sibit] [jiSıbit] & I played \\
\hline & /rsii:f/ & [?Irsi:f] & pavement \\
\hline
\end{tabular}

A jump in the vocabulary size was witnessed at this age. This has shown the emergence of new Arabic consonantal sequences that had not been produced so far. The first of such sequences was a nasal that was followed by a fricative-reversal. The subject handled this sequence by inserting an epenthesic vowel and the sequence was produced un-tackled in very few cases (Table 15). 
Table 15. a nasal+ a fricative

\begin{tabular}{llll}
\hline Age & Arabic & & Glossary \\
\cline { 2 - 4 } & Target & Child's & \\
& words & Production & \\
\hline $2 ; 05$ & $/$ nfu:t/ & {$[$ nfu:t] } & we enter \\
$2 ; 06$ & $/$ mfallem/ & {$[$ [aiajjem] } & teacher \\
$2 ; 10$ & $/ n$ fu:f/ & {$[$ [nfu:f] } & we see \\
$3 ; 01$ & $/$ SYallem/ & {$[$ ma?ajjem] } & teacher \\
$3 ; 03$ & $/$ nsi:t/ & [nisi:t] & I forgot \\
\hline
\end{tabular}

Another newly appeared sequence was the one formed of a stop followed by a nasal. This sequence was broken by an epenthetic vowel. (Table 16).

Table 16. a stop+ a nasal

\begin{tabular}{llll}
\hline Age & Arabic & & Glossary \\
\cline { 2 - 4 } & Target & Child's & \\
& words & Production & you sleep \\
& $/$ tna:m/ & {$[$ nna:m] } & two \\
$3 ; 04$ & $/$ tne:n/ & {$[$ tene:n] } & tails \\
\hline
\end{tabular}

A third Arabic sequence that newly appeared at this age was formed of a fricative that was followed by another fricative-plateau cluster. This sequence was tackled by either inserting a syllable- prothesis or epenthesizing a vowel. However, it was produced properly at the age of 3;01 (Table 17).

Table 17. africative+ a fricative

\begin{tabular}{|c|c|c|c|}
\hline \multirow[t]{3}{*}{ Age } & \multicolumn{2}{|l|}{ Arabic } & \multirow[t]{3}{*}{ Glossary } \\
\hline & Target & Child's & \\
\hline & words & Production & \\
\hline $2 ; 04$ & /hșa:n/ & [hıșa:n] & horse \\
\hline $3 ; 01$ & /hșa:n/ & [hșa:n] & horse \\
\hline \multirow[t]{2}{*}{$3 ; 04$} & /șhu:n/ & [suhu:n] & dishes \\
\hline & /zri:r/ & [zıri:j] [?ızri:j] & small \\
\hline
\end{tabular}

At this stage, a sequence formed of a nasal followed by a liquid-reversal also occurred. The subject chose segment deletion, vowel epenthesis, and un-tackled production (Table 18).

Table 18. a nasal+ a liquid

\begin{tabular}{llll}
\hline Age & Arabic & Glossary \\
\cline { 2 - 4 } & Target & Child's & \\
& words & Production & \\
\hline $2 ; 05$ & $/$ mra:je/ & [maja:je] & mirror \\
& $/$ nru:h/ & [ju:h] & we go \\
$3 ; 01$ & $/$ mra:je/ & [mja:je] & mirror \\
$3 ; 02$ & $/$ mra:je/ & [mja:je] & mirror \\
$3 ; 04$ & $/$ nru:h/ & [nju:h] & we go \\
\hline
\end{tabular}

Another sequence exclusive to Arabic cluster was formed of a nasal followed by another nasal-plateau. This was first truncated by deleting the first $/ \mathrm{m} /$ sound and three months later the sequence was produced properly (Table 19). 
Table 19. a nasal+ a nasal

\begin{tabular}{llll}
\hline Age & Arabic & & Glossary \\
\cline { 2 - 4 } & Target & Child's & \\
& words & Production & good \\
& $/ \mathrm{mni}: \mathrm{h} /$ & {$[\mathrm{ni}: \mathrm{h}]$} & good \\
\hline $2 ; 07$ & $/ \mathrm{mni}: \mathrm{h} /$ & {$[\mathrm{mni}: \mathrm{h}]$} & s
\end{tabular}

The last Arabic sequence that appeared at this stage was the one formed of a stop followed by another stop-plateau. The child produced two sequences of such a type, including $/ \mathrm{bt} / \mathrm{and} / \mathrm{kb} /$. The former sequence was truncated into a singleton and the later was broken by an epenthetic vowel (Table 20).

Table 20. a stop+ a stop

\begin{tabular}{llll}
\hline Age & Arabic & & Glossary \\
\cline { 2 - 4 } & Target & Child's & \\
& words & Production & big \\
\hline $2 ; 06$ & $/$ kbi:r/ & {$[$ kibi:j] [ktbi:u] } & you are writing \\
$3 ; 01$ & $/$ btuktub/ & {$[$ [uttub] } & a lot of \\
$3 ; 03$ & $/$ kti:r/ & {$[$ kiti:j] } & \\
\hline
\end{tabular}

The child's occasional proper production of the clusters indicated the stage at which the child had started to recognize the marked cluster in the form of Arabic he was exposed to. The occasional production of the proper branching onset signalled the starting point of acquiring segment sequences in onset position. The recognition of Arabic branching onsets was delayed compared to the recognition of English branching onsets. The child's occasional segment deletion at this stage reflected the segment deletion that was used at the previous stage. In other words, the English or the Arabic segment that was deleted in stage 1 was also deleted in this stage. Therefore, nothing can be added in this regard. Moreover, new repair strategies were used along with cluster truncation. Epenthesizing a vowel helped in repairing English and Arabic sequences. Inserting a syllable-prothesis and using geminates helped in repairing Arabic sequences.

This vowel epenthesis reflected the child's rhythmic preference for CV pattern over CC pattern. The insertion of a vowel would turn the problematic marked pattern-C1C2 into a non-problematic unmarked pattern-C1VC2 (Freitas, 2003; Jakobson, 1968; McCarthy and Prince, 1986; Selkirk, 1982;). The stages of the acquisition of onset clusters that were suggested by Fikkert (1994) did not involve this epenthesis repair strategy. Epenthesis, however was used to repair onset clusters by children acquiring different languages in the literature. The following data set provides samples of children's production with vowel epenthesis used to simplify consonant cluster in onset position.

Data Set 3. Vowel Epenthesis in this Study and in other Related Studies

\section{Portugues (Freitas 2003)}

$\begin{array}{cl}\text { Child's Production } & \begin{array}{l}\text { Target Form } \\ \text { [kiredi] }\end{array} \\ \text { [firwde] } & / \text { fradi/ } \\ \text { [filojf] } & / \text { flort } \int /\end{array}$

Hebrew (Block 2011)

$\begin{array}{ll}\text { [keta'na] } & \text { /kta'na/ } \\ \text { [gado'la] } & \text { /gdo'la/ } \\ \text { [Sefa'nim] } & \text { / ffa'nim/ }\end{array}$

Ammani Arabic (Daana 2009)

$\begin{array}{ll}\text { [maiass] } & \text { /m?așs/ } \\ \text { [kıla:b] } & \text { /klaa:b/ } \\ \text { [rufu:f] } & \text { /rfu:f/ }\end{array}$




\section{English (this subject)}

$\begin{array}{ll}\text { [fawauə] } & \text { flower } \\ \text { [fuwu:t] } & \text { fruit } \\ \text { [sənerk] } & \text { snake } \\ \text { Arabic (this subject) } & \\ \text { [suhu:n] } & \text { /șhu:n/ } \\ \text { [zıri:j] } & \text { /zri:r/ } \\ \text { [maja:je] } & \text { /mra:je/ }\end{array}$

The use of prothesis as a repair strategy reflected the child's ability of manipulating the marked CC pattern by inserting a syllable formed of a glottal followed by a short vowel /RI/. The resulting production would allow syllable contact instead of the branching onset word-initially-C1C2 $\rightarrow \mathrm{CVC} 1 \mathrm{C} 2$ (Figure 1).
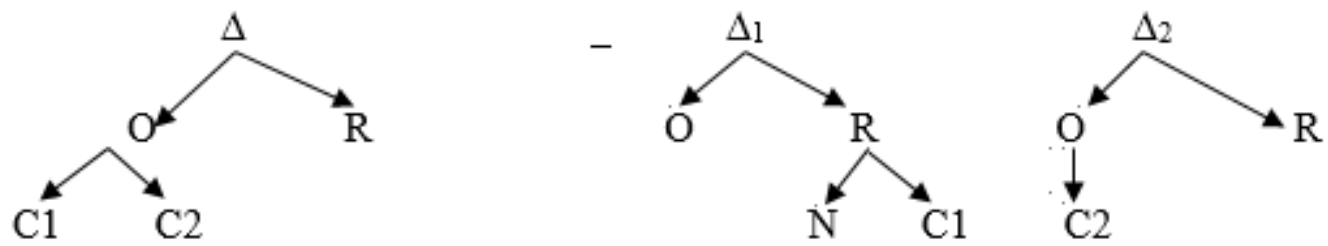

Figure 1. $\mathrm{C} 1 \mathrm{C} 2 \rightarrow \mathrm{CVC} 1 \mathrm{C} 2$

This study was unable to justify the fact that this repair strategy was applied exclusively to Arabic data. Prothesis was not listed in the stages proposed by Fikkert (1994) either. It was used by Daana's subjects acquiring Ammani Arabic (Daana, 2009).

Data Set 4. Prothesis in this Study and in other Related Studies

$\begin{array}{ll}\text { Ammani Arabic (Daana 2009) } \\ \text { Child's Production } & \text { Target Form } \\ \text { [?Ilfu:f] } & \text { /rfu:f/ } \\ \text { [?Imla:je] } & / \mathrm{mra}: \mathrm{je} / \\ \text { [?I3ma:1] } & / 3 \mathrm{ma}: 1 /\end{array}$

Arabic (This subject)

$\begin{array}{ll}\text { [RIjri:t] } & \text { / } \text { ri:t/ } \\ \text { [?in?ass] } & \text { /m?așs/ } \\ \text { [?iju:d] } & \text { /Rru:d/ }\end{array}$

The child chose to geminate either element of the cluster only once. Studies on the acquisition of other languages did not involve this repair strategy. However, it was used by Daana's subjects mainly to handle consonant clusters in medial position (Daana, 2009); therefore, nothing further can be added here.

To point out the main characteristics of the child's production during this age-stage, it is important to bear in mind the following:

- This stage can be recognized as an intermediate stage of the acquisition of branching onsets.

- The repair strategies that were used throughout this stage included:

1. Epenthesis in English and Arabic: $\mathrm{C} 1 \mathrm{C} 2 \rightarrow \mathrm{C} 1 \mathrm{VC} 2$

2. Prothesis $\mathrm{C} 1 \mathrm{C} 2 \rightarrow \mathrm{CVC} 1 \mathrm{C} 2$ in Arabic

3. Geminates $\mathrm{C} 1 \mathrm{C} 2 \rightarrow \mathrm{C} 1 \mathrm{C} 1$ or $\mathrm{C} 1 \mathrm{C} 2 \rightarrow \mathrm{C} 2 \mathrm{C} 2$ in Arabic

4. Very few cases of segment deletion which mirrored segment deletion in the first stage 
These repair strategies co-occurred with the proper production of the target cluster at this stage.

\subsection{Stage Three}

The last age- stage was between 3;06 and 4;06. Throughout this stage the child started to produce the target clusters similar to what had been perceived, except for the occasional replacement of English /l/ with a [j] or [w], /r/ with a [w], and the occasional replacement of Arabic /1/, and /r/ with [j]. No form of repair strategies was used at this stage. Representative data of all types of consonantal sequences in word-initial position is shown in table 21.

Table 21. Representative Data Set of the Child's Production during Age-Stage 3

\begin{tabular}{|c|c|c|c|c|c|}
\hline \multirow[t]{2}{*}{ Age } & \multicolumn{2}{|l|}{ English } & \multicolumn{3}{|l|}{ Arabic } \\
\hline & $\begin{array}{l}\text { Target } \\
\text { words }\end{array}$ & $\begin{array}{l}\text { Child's } \\
\text { productions }\end{array}$ & $\begin{array}{l}\text { Target } \\
\text { words }\end{array}$ & $\begin{array}{l}\text { Child's } \\
\text { production }\end{array}$ & Glossary \\
\hline \multirow[t]{27}{*}{$3 ; 06$} & three & 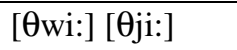 & /hra:m/ & [hja:m] & blanket \\
\hline & fridge & [fredz] & $/ \int \mathrm{rrbt} /$ & {$\left[\int j i b t\right]$} & I drank \\
\hline & sleep & [sji:p] & /Sri:t/ & [Sji:t] & cassette \\
\hline & frog & [fwog] & /fla:m/ & [Sla:m] & flags \\
\hline & sly & [swaI] & /zla:m/ & [zja:m] & men \\
\hline & train & [treIn] & /tre:n/ & [tre:n] & train \\
\hline & tractor & [træktə] & /tra:b/ & [tra:b] & soil \\
\hline & tractor & [træktə] & & & \\
\hline & trampoline & [træmpəli:n] & & & \\
\hline & blanket & [blæクket] & & & \\
\hline & closed & [kləuzd] & & & \\
\hline & cloudy & [klaudi] & & & \\
\hline & crab & [kræb] & & & \\
\hline & special & [spesəj] & / Stare:tha/ & [ $\int$ tare:tha] & I bought it $(\mathrm{F})$ \\
\hline & speak & [spi:k] & /ftu:r/ & [ftu:r] & \\
\hline & space & [speis] & & & \\
\hline & sky & [skaI] & & & \\
\hline & skate & [skeit] & & & \\
\hline & skirt & [sk3:t] & & & \\
\hline & scooter & [sku:tə] & & & \\
\hline & school & [sku:j] & & & \\
\hline & stand & [stænd] & & & \\
\hline & stop & [stop] & & & \\
\hline & story & [sto:wi] [sto:ji] & & & \\
\hline & sticker & [strkə] & & & \\
\hline & still & [strw] & & & \\
\hline & steam & [sti:m] & & & \\
\hline \multirow[t]{6}{*}{$3 ; 07$} & slowly & [swəuji:] & /zla:m/ & [zla:m] & men \\
\hline & blouse & [blauz] & /tru:h/ & [tju:h] & you will go \\
\hline & green & [gri:n] [gwi:n] & & & \\
\hline & grass & [gra:s] & & & \\
\hline & drink & [drınk] & & & \\
\hline & break & [breık] [bwerk] & & & \\
\hline
\end{tabular}




\begin{tabular}{|c|c|c|c|c|c|}
\hline & clean & [kji:n] [kli:n] & /kla:b/ & [kla:b] & $\operatorname{dogs}$ \\
\hline & present & [prezənt] [pwezənt] & /Rru:d/ & [?ru:d] & monkeys \\
\hline & press & [pres] & /dmu:S/ & [dmu:Y] & tears \\
\hline & pray & [preI] & & & \\
\hline & snow & [snəu] & /3ma:1/ & [zma:j][3ma:j] & camels \\
\hline & small & [smoj] & /hma:r/ & [ћma:j] & donkey \\
\hline & snake & [snerk] & & & \\
\hline \multirow[t]{13}{*}{$3 ; 08$} & slide & [sward] & & & \\
\hline & throw & {$[\theta$ wəv $]$} & & & \\
\hline & front & [fwont] & & & \\
\hline & cried & [kraId] & & & \\
\hline & please & [pli:z] & & & \\
\hline & broke & [bwəuk] [brəuk] & & & \\
\hline & bread & [bred] & & & \\
\hline & climbing & [klaimin] & & & \\
\hline & friend & [frend] & & & \\
\hline & smoothy & [smu:ði:] & /sna:n/ & [sna:n] & teeth \\
\hline & & & /Smeltha/ & [Smeletta] & I did it \\
\hline & special & [sp3səl] & & & \\
\hline & scoop & [sku:p] & & & \\
\hline \multirow[t]{4}{*}{$3 ; 09$} & play & [pler] [pjer] & & & \\
\hline & dragon & [drægən] & & & \\
\hline & speaking & [spi:kın] & & & \\
\hline & school & [sku:1] & & & \\
\hline \multirow[t]{5}{*}{$3 ; 10$} & friend & [fwend] [frend] & & & \\
\hline & slept & [slept] & & & \\
\hline & dream & [dri:m] & & & \\
\hline & crocodile & [krokədail] & & & \\
\hline & snake & [snerk] & / $\mathrm{mu}: \mathrm{s} /$ & [Smu:s] & suns \\
\hline $3 ; 11$ & crackers & [krækəz] [kwækəz] & & & \\
\hline \multirow[t]{7}{*}{$4 ; 01$} & bring & [brin] & & & \\
\hline & British & [brittf] & & & \\
\hline & preschool & [prisku:1] & & & \\
\hline & spider & [spaidə] & & & \\
\hline & Scottish & [skotiS] & & & \\
\hline & station & 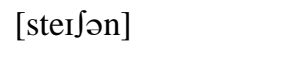 & & & \\
\hline & stay & [ster] & /sta?mal/ & [sta?mal] & he used \\
\hline $4 ; 02$ & Friday & [fwarder] & /zba:1/ & [3ba:j] [zba:1] & mountains \\
\hline \multirow[t]{2}{*}{$4 ; 03$} & sleep & [sleep] & & & \\
\hline & fruit & [fwu:t] & & & \\
\hline $4 ; 05$ & three & [Өri:] & & & \\
\hline
\end{tabular}


Table 21 has shown that the child's English and Arabic productions matched his input in both languages. A closer look at the child's age revealed that the acquisition of English cluster took place earlier than Arabic cluster. It can be ascertained that at this stage the child was able to produce the cluster of almost all sorts of English and Arabic consonantal sequences. However, the child still had an articulatory problem with the production of /r/ and /l/ sounds. In very few cases, the child produced these sounds correctly.

The child's production of the Arabic consonantal clusters that do not exist in English was faithful to the input (Table 22).

Table 22. Representative Data Set of the Child's Consonantal Sequences Exclusive to Arabic

\begin{tabular}{|c|c|c|c|}
\hline \multicolumn{4}{|c|}{ Arabic } \\
\hline \multirow[t]{2}{*}{ Age } & Target & Child's & Glossary \\
\hline & words & Production & \\
\hline \multirow[t]{6}{*}{$3 ; 06$} & /kbi:r/ & [kbi:j] [kbi:r] & big \\
\hline & /kti:r/ & [kti:j][kti:r] & a lot of \\
\hline & /zri:r/ & [zri:j] [zri:u][zri:r] & small \\
\hline & /mni:h/ & [mni:ћ] & good \\
\hline & /mra:je/ & [mja:je] [mra:je] & mirror \\
\hline & /nru:h/ & [nju:ћ] [nru:ћ] & we go \\
\hline \multirow[t]{4}{*}{$3 ; 07$} & /tfaddal/ & [tfaddaj] & come in \\
\hline & /hșa:n/ & [hșa:n] & horse \\
\hline & /dna:b/ & [nna:b] [dna:b] & tails \\
\hline & /kfu:f/ & [kfu:f] & gloves \\
\hline \multirow[t]{2}{*}{$3 ; 08$} & /tfu:t/ & [tfu:t] & you enter \\
\hline & /btuktub/ & [btuktub] & you are writing \\
\hline \multirow[t]{3}{*}{$3 ; 09$} & /tna:m/ & [tna:m] & you sleep \\
\hline & /tne:n/ & [tne:n] & two \\
\hline & /șhu:n/ & [shu:n] & dishes \\
\hline \multirow[t]{9}{*}{4} & /miallem/ & [miajjem] & teacher \\
\hline & /nkasrat/ & [nkasjat] & it broke $(\mathrm{F})$ \\
\hline & /nkasar/ & [nkasaj] & it broke $(\mathrm{M})$ \\
\hline & /nsi:t/ & [nsi:t] & I forgot \\
\hline & /nfu:t/ & [nfu:t] & we enter \\
\hline & /nfu:f/ & [nfu:f] & we see \\
\hline & /rși:f/ & [rsi:f] & pavement \\
\hline & /miasss/ & [ma?ass] [m?asss] & a pair of scissors \\
\hline & /mba:reh/ & [nba:jeћ][mba:jeћ] & yesterday \\
\hline \multirow[t]{2}{*}{$4 ; 02$} & /rfu:f/ & [rfu:f][/jfu:f] & shelves \\
\hline & /lisıbit/ & [jSIbIt] & I played \\
\hline
\end{tabular}

Table 22 has shown that Arabic core cluster are acquired first and Arabic reversals are acquired the last. This delayed production of the marked forms was evidenced in other studies on monolingual children (Elbert, Dinnsen, \& Powell, 1984; Gierut, 1999) as well as bilingual children (Keffala, Barlow \& Rose, 2016; Kehoe, 2002; LIeo and Cortes, 2013).

As a matter of fact, the child, at this stage, started producing English words with three consonants in the onset position. However, the child did not use any Arabic word with three-consonants in onset position at this stage. 
Table 23. a fricative + a stop + a liquid

\begin{tabular}{lll}
\hline Age & Target Words & Child's Productions \\
\hline $3 ; 06$ & street & [stwi:t] \\
& straw & {$[$ stwo:] } \\
& spring & {$[$ spjin] } \\
$3 ; 07$ & scratchy & {$[$ skwæt $\mathrm{ji}]$} \\
$3 ; 08$ & strawberry & {$[$ stwobəwI] } \\
4 & strong & [stwoj] \\
\hline
\end{tabular}

\section{Conclusion and Recommendation}

The study has traced the development of branching onsets in the speech of a bilingual child whose two first languages are Arabic and English. Data analysis revealed the stages the child passed through along the process of acquiring branching onsets in English and Arabic. Data analysis also shed light on the repair strategies that were used by the child to change the marked $\mathrm{C} 1 \mathrm{C} 2$ pattern to the unmarked pattern during these stages. The strategies to which the child resorted in order to turn problematic structure into non-problematic structure in light of the child's rhythmic preference along the gradual course of the acquisition of branching onsets were summarized in three stages. At stage one, the child truncated all target clusters either to the left segment or to the right segment. The child's data in both languages attested divergent production with regard to the onset sonority pattern. In some cases the child's production conformed to the SSP but in some other cases his production was counter to the sonority pattern reduction.

At stage two, the child's repair strategies alternated between epenthesis, prothesis, and the use of geminates. Epenthesis was used in English and Arabic; whereas, prothesis and geminates were exclusive to Arabic language. This stage was considered a transitional or an intermediate stage. However, at stage three the child's production matched the input in which all the target clusters were produced properly in both languages.

Arabic clusters took longer time to occur as compared to English clusters. Despite the fact that the child was exposed to both languages soon after his birth, and by virtue of the fact that he was exposed to English more than Arabic, the child produced more English target words than Arabic. Moreover, the most unmarked Arabic type of cluster emerged before the others. The child showed mastery of core clusters before plateaux and reversals. The child took longer time to produce plateaux and reversals by virtue of perceptual, articulatory, and sonority reasons.

This is the first study to trace the developmental path of onset clusters and the use of the repair strategies by a bilingual child whose two first languages are Arabic and English. The results show consistency with results of other research in terms of the child's English data. The results also show consistency with results of the only research that handled the acquisition of onset cluster in the same Arabic dialect. Thereforeother research on the acquisition of onset clusters in other forms of Arabic is recommended. Only then, patterns of the emergence of consonantal sequences and repair strategies might be found in terms of the child's Arabic data.

\section{References}

Al-Amayreh, M. (1994). A Normative Study of the Acquisition of Consonant Sounds in Araic. PhD Dissertation: University of Florida.

Bladon, A. (1986). Phonetics for Hearers in G. McGregor (ed.) Language for Hearers. Oxford: Pergaman Press, $1-24$.

Block, T. (2011). Simplification Strategies in the Acquisition of Consonant Clusters in Hebrew. MA Thesis. Tell-Aviv University.

Brown, D. (2015). Principles of Language Learning and Teaching, 5th edition. UK.: Longman.

Butt, M. (1992). Sonority and the Explanation of Syllable Structure. Linguistische Berichte, 137, 45-67.

Carr, Ph. (1999). English Phonetics and Phonology. UK.: Blackwell Publishers.

Clements, G. N. (1990). The Role of the Sonority Cycle in Core Syllabification. Papers in laboratory phonology 1: Between the Grammar and Physics of Speech, 283-333. Cambridge: Cambridge University Press. https://doi.org/10.1017/CBO9780511627736.017 
Daana, H.A.. (2009). The Development of Consonant Clusters, Stress and Plural Nouns in Jordanian Arabic Child Language. PhD diss. UK.: The University of Essex. Google Scholar.

Elbert, M., Dinnsen, D., \& Powell, T. (1984). On the prediction of Phonologic Generalization Learning Patterns. Journal of Speech and Hearing Disorders, 49(3), 309-317. https://doi.org/10.1044/jshd.4903.309

Fikkert, P.(1994). On the Acquisition of Prosodic Structure. Leiden:HIL.

Freitas, J. M. (2003) The Acquisition of Onset Clusters in European Protuguese. In J. Meisel (ed.) Probus, 15(1), 27-46.

Gierut, J. A. (1999). Syllable Onsets: Clusters and Adjacents in Acquisition. Jornal of Speech, Language, and Hearing Research, 42(3), 708-726. https://doi.org/10.1044/jslhr.4203.708

Gnanadesikan, A. (1995). Markedness and Faithfulness Constraints in Child Phonology. ROA-67.MS. https://doi.org/10.1017/CBO9780511486418.004

Hammond, M. (1999). The Phonology of English: A Prosodic Optimality-Theoretic Approach.. UK.: Oxford University Press. https://doi.org/10.1017/S0952675701004134

Hide, M.J. (2007). Treatment Effects on Cluster Development in the Speech of 4-Year-Old Children with Speech Disorder. Master Thesis. University of Canterbury.

Jakobson, R.. (1968). Child Language, Aphasia and Phonological Universals, 72. Walter de Gruyter GmbH \& Co KG. https://doi.org/10.1515/9783111353562

Jun, J. (2004). Place Assimilation. In Hayes, B. Kirchner, R. and Steriade, D. (eds) Phonetically based phonology, 58-86. Cambridge: Cambridge University press. https://doi.org/10.1017/CBO9780511486401.003

Keffala, B., Barlow, J. \& Pose, Sh. (2016). Interaction in Spanish-English Bilinguals' Acquisition of Syllable Structure. International Journal of Bilingualism, 22(1), 16-37. https://doi.org/10.1177/1367006916644687

Kehoe, M. M. (2002). Developing Vowel Systems as a Window to Bilingual Phonology. International Journal of Bilingualism, 6(3), 315-334. https://doi.org/10.1177/13670069020060030601

Kirk, C. \& Demuth, K. (2005). Asymmetries in the Acquisition of Word-Initial and Word-Final Consonant Clusters. Journal of Child Language, 32(4), 709-734. https://doi.org/10.1017/S0305000905007130

Ladefoged, P. (2006). Course in Phonetics (5 th edition) Australia: Thomson Wadsworth. Jovanovich. https://trove.nla.gov.au/version/207966741

Levelt, C., Schiller, N. \& Levelt, W. (2000). The Acquisition of Syllable Types. Language Acquisition, 8(3), 237-264. https://doi.org/10.1207/S15327817LA0803_2

LIeo, C. \& Coltes, S. (2013). Modelling the Outcome of Language Contact in the Speech of Spanish-German and Spanish-Catalan Bilingual Children. In J. Kabatek, and L. Loureido (eds.), Special Issue on Language Competition and Linguistic Diffusion: Interdisciplinary Models and Case Studies. International Journal of the Sociology of Language, 221, 101-125. Google Scholar.

Lleo, C. \& Prinz, M. (1996). Consonant Clusters in Child Phonology and the Directionality of Syllable Structure Assignment. Journal of Child Language, 23(1), 31-56. https://doi.org/10.1017/S0305000900010084

Lleo, C. (1990). Homonymy and Reduplication: An Extended Availability of two Strategies in Phonological Acquisition. Journal of Child Language, 17(2), 267-278. https://doi.org/10.1017/S0305000900013763

Lieven, E. (2010). Bilingual Language Acquisition. Human Development, 53(5), 256-263. https://doi.org/10.1159/000321285

Manuel, Sh.Y. (1991). Some Phonetic Bases for the Relative Malleability of Syllable-Final Versus Syllable-Initial Consonants. In Proceedings of the 12th International Congress of Phonetics Sciences, 5, 118-121.

McCarthy, J. J., \& Prince, A. (1986). Prosodic Morphology. University of Massachusetts at Amherst and Rutgers University Ms.

Ohala, J.J. (1990). The Phonetics and Phonology of Aspects of Assimilation. Papers in laboratory phonology, 1, 258-275. https://doi.org/10.1017/CBO9780511627736.014

Pater, J., \& Barlow, J. A. (2003). Constraint Conflict in Cluster Reduction. Journal of child language, 30(3), 487-526. https://doi.org/10.1017/S0305000903005658 
Ratcliffe, R. (1998). The Broken Plural Problem in Arabic and Comparative Semitic. Amesterdam: John Benjamin Publishing Company. https://doi.org/10.1075/cilt.168

Rose, Y. (2000). Headedness and Prosodic Licensing in the L1 Acquisition of Phonology. PhD diss. McGill University. https://doi.org/10.1075/arla.2.06ros

Scobbie, J. M., Gibbon, F., Hardcastle, W. \& Fletcher, P. (2000). Covert Contrast as a Stage in the Acquisition of Phonetics and Phonology. In M. Broe and J. Pierrehumbert (eds.) Papers in Laboratory Phonology: Acquisition and the Lexicon V. Cambridge: Cambridge University Press, pp. 194- 207.

Selkirk, E. O. (1984). On the Major Class Features and Syllable Theory. In Aronoff, M. Oehrle, R. (eds.). Language Sound Structure. Cambridge, MA: MIT Press.

Selkirk, E.O. (1982). The Syllables. In Harry van der Hulst and Norval Smith (eds.). The structure of phonological representations, 2, 337-383. Holland, Dordrecht: Foris Publishers.

Stites, J., Demuth, K. \& Kirk, C. (2004). Markedness vs. Frequency Effects in Coda Acquisition. In Proceedings of the 28th annual Boston University conference on language development, 2, 565-576.

Templin, M.C. (1957). Certain Language Skills in Children; their Development and Interrelationships. Monograph Series No. 26. Minneapolis University of Minnesota Press: Minnepolis. https://doi.org/10.1086/459642

Watson, J. (2002). The Phonology and Morphology of Arabic. Oxford University Press. https://doi.org/10.1017/S0952675703004548

Wright, R. (2004). A Review of Perceptual Cues and Cue Robustness. In Hayes, B., Kirchner, R. and Steraide, D. (eds.) Phonetically based phonology, 34-57. Cambridge University press. https://doi.org/10.1017/CBO9780511486401.002 